\title{
Do precious metal spot prices influence each other? Evidence from a nonparametric causality-in-quantiles approach
}

\author{
Vaneet Bhatia \\ Finance Area, Indian Institute of Management Raipur \\ Email id: vaneet.b@outlook.com \\ Debojyoti Das \\ Finance Area, Indian Institute of Management Raipur \\ Email id: debojyoti.d@outlook.com \\ Aviral Kumar Tiwari \\ Center for Energy and Sustainable Development (CESD), \\ Montpellier Business School, Montpellier, France \\ Email id: aviral.eco@gmail.com \\ Muhammad Shahbaz \\ Center for Energy and Sustainable Development (CESD), \\ Montpellier Business School, Montpellier, France \\ Email id: shahbazmohd@live.com \\ Haslifah M. Hasim \\ Department of Mathematical Sciences, University of Essex \\ Wivenhoe Park, Colchester CO4 3SQ, United Kingdom \\ E-mail: hhashim@essex.ac.uk
}

\begin{abstract}
Using a quantile causality approach, we examine the causal relationship among the spot prices of precious metals (gold, silver, platinum and palladium) through mean and variance. This methodology also allows investigation of the causality among precious metals during recessions, booms and normal market states. Employing daily spot price data from April 2000 to July 2016 we found evidence of bi-directional causality in mean and variance among the prices of precious metals. Results indicate a strong causality for the middle quantiles (normal time periods). Robustness of results is also examined by employing weekly spot price data. Overall our results have significant implications for policy makers, portfolio managers and investors.
\end{abstract}

Keywords: Precious metals; Causality-in-quantiles; Gold; Silver; Platinum; Palladium 


\section{Introduction}

The safe-haven properties of precious metals have offered substantial impetus to policy makers and scholars alike to examine their multi-faceted behavior, especially as an alternative investment instrument. Studies in the recent past have suggested the favorable role of precious metals, particularly gold, in hedging and portfolio diversification strategies (Baur and McDermott, 2010; Reboredo, 2013a). Nonetheless, some studies also argue against such diversification benefits (Lucey and Li, 2015; Reboredo, 2013b). However, those studies which argue in favor of the use of precious metals for investments overwhelm those arguing the unsuitability of precious metals as a diversification avenue. Most of the studies have argued in favor of the usage of precious metals for investments, such as the following: safe investment target, a hedging tool against risk and inflation, and highly liquid investment, among others. This hedging property of precious metals is evident from earlier literature, such as that by Jain and Biswal (2016), who argue that investments in precious metals, particularly gold, greatly increase during economic shocks. Baur and McDermott (2010) also report that the nominal prices of gold rose by 42 per cent on the eve of the financial crisis, i.e., July 2007. Other scholars also report gold to be uncorrelated with financial assets during periods of high volatility or financial crisis (Baur and Lucey, 2010; Baur and McDermott, 2010), therefore making it an ideal hedging instrument.

Despite substantial empirical evidence on multifarious aspects of precious metals, there are few studies that investigate interactive and transitive behavior among them. Hammoudeh et al. (2011) examine the dynamics of correlation and volatility in price returns of gold, silver, platinum and palladium and suggest implications for risk management. Sensoy (2013) reports a one-way volatility shift contagion effect from gold to other precious metals and from silver to platinum and palladium. Thus, in this context, the literature encounters some pertinent questions, such as: (a) Is it only gold that dictates the prices of other precious metals? Or (b) do other precious metals (silver, platinum or palladium) also lead gold prices? Or (c) do precious metals influence each other's prices? These questions are intriguing, and to the best of our knowledge, are yet to be answered. Therefore, the objective of this paper is to investigate the causality among precious metal prices by employing the quantile causality technique proposed by Balcilar et al., (2016a). We believe such analysis will help investors and policy makers originate better decisions regarding precious metal price movements.

Though earlier literature emphasizes the relationship among gold, silver, platinum and palladium, they cannot be considered as a single asset class (Pierdzioch et al., 2016). Batten, Ciner and Lucey (2010) analyzed the spillovers among four precious metals and suggested a weak integration between gold, silver, platinum and palladium. Interestingly, Lucey and $\mathrm{Li}$ (2015) argued that silver, platinum and palladium can exhibit safe-haven properties during times when gold loses its safe-haven characteristic. Agyei-Ampomah, Gounopoulos and Mazouz (2014) revealed the ability of gold to hedge against losses in sovereign bond issues in the case of countries with serious debt problems. Furthermore, they suggested the hedging ability of metals other than gold in sovereign bond market losses during periods of jitters in financial markets. 
The existing literature provides useful information on precious metal dynamics; however, little is known about dependence and causality among precious metal prices. Therefore, in this study, we use the recent causality technique proposed by Balcilar et al., (2016a) to investigate the predictability of one precious metal price by the prices of other precious metals through mean and variance. We employ daily spot price data of gold, silver, platinum and palladium for the period of April 1, 2000 to July 25, 2016. To check the robustness of our results, we employ the same methodology on weekly spot prices of precious metals over the same time horizon. Our results show a bi-directional causality among precious metal prices in mean and variance. However, the causality among precious metals varies to some extent between daily and weekly prices.

Our contribution to the literature on precious metals is three-fold. First, the non-parametric quantile approach allows us to consider all the market conditions at the same time (low or high volatility or any other economic shocks). Therefore, the approach allows us to investigate the conditions under which one precious metal price responds to other precious metal prices. Second, we consider both first (mean) and second moments (variance) to analyze the causality between prices of different precious metals. Precious metals may not have causality in mean but could have predictive powers in variance (volatility). Predictive power in volatility could be more useful for better portfolio diversification strategies. Third, we use the application of a recent methodology by Balcilar et al. (2016a) to analyze the dynamics among precious metals.

The rest of the paper is organized as follows. In section 2 we provide a concise review of literature. The stochastic properties of the data are mentioned in section 3 . The estimation methodology is discussed in section 4 . The empirical results are presented in section 5. The result of the robustness test is presented in section 6. Finally, we conclude in section 7.

\section{Review of Literature}

The earlier literature analyzing the dynamics of precious metals can be segregated into different themes. The first group of studies analyzes the dynamics between precious metal prices considering macro-economic factors. The second group investigates volatilities in precious metals and their modeling. The third class of literature examines conditional volatilities, correlation dependence and spillover effects involving precious metals. The fourth group focuses upon the forecasting of value at risk (VaR) and the modeling of precious metal prices. The last group investigates the hedging properties of precious metals.

On the impact of a volatile economic environment on the dynamics of the precious metal market, Morales and Andreosso-O'Callaghan (2011) investigated the role of Asian and global financial crises in determining the behavior of precious metal markets. The researchers argued that precious metal prices, their volatility and information contained in the precious metal markets influence volatility in other markets. Gold prices and movements in the gold market also reportedly influence the remainder of the metal market. Cochran, Mansur and Odusami (2012) reported that volatility in the returns of precious metals has increased after the 2008 crisis. On the one hand, Vivian and Wohar (2012) 
reported no abrupt increase in volatility during the crisis period. Batten, Ciner and Lucey (2010) suggested that monetary variables impact the gold volatilities, but the same is not true for silver. The authors also suggested that gold, palladium, silver and platinum are too distinct to be classified as a single metal class. On the other hand, Sari, Hammoudeh and Soytas (2010) argued that precious metals respond to any shock in the exchange rate or shock in the prices of other precious metals. Wang and Chueh (2013) suggested that interest rates negatively influence future gold prices. Reduced interest rates signal to investors that the dollar will depreciate; therefore, investors will ultimately move their capital to the gold market for preservation and speculation. Ming, Yang, and Cheng (2016) suggested a double nature of gold prices, whereby they argued that, in the long term, speculation and economic events influence gold prices and that, in the short term, gold acts as a safe investment.

Regarding conditional returns and volatilities of precious metals, Arouri, Hammoudeh, Lahiani and Nguyen (2012) suggested a long-range dependence between precious metals and argued that the long memory process explains conditional volatility better than structural breaks. Demiralay and Ulusoy (2014) also found evidence indicating the volatility among precious metals to be a long-range dependent process. Hammoudeh and Yuan (2008) analyzed the volatility of gold, silver and copper and reported that gold and silver have similar volatility persistence but that it is greater than copper. The authors indicated that past oil shocks had different impacts on gold, silver and copper, and a crisis period such as the Iraq war increased the metals' volatility. Baur (2012) investigated the impacts of positive and negative shocks on the volatility of gold and suggested an inverted asymmetric response. Positive shocks result in higher volatility than negative shocks. Investors perceive positive shocks to gold as the arrival of adverse conditions and uncertainty in other asset classes.

With regard to the connection between precious metals, Ciner (2001) suggested an unstable relationship between gold and silver prices. The author reported that the long-run relationship between gold and silver prices disappeared in the 1990s. Later, Lucey and Tully (2006) suggested a long-run relationship between gold and silver prices but also reported aberrations in the short run. Sensoy (2013) analyzed the changing relationship between precious metals and reported that gold influences the behavior of other precious metals. Furthermore, the author argued that silver also influences the prices of platinum and palladium. Baur and Tran (2014) analyzed the long-run relationship between gold and silver prices with a focus on the impact of bubbles and financial crises. The authors report a co-integration relationship between gold and silver and the role of financial crises. However, the researchers also reported a lack of a stable relationship between gold and silver. Antonakakis and Kizys (2015) suggested in their study that changes in gold prices are transmitted (spillover) to other assets but are conditional on time and event-specific patterns. More recently, Kang, McIver and Yoon (2016) reported that gold and silver apparently serve as sources of information transmission among the commodity futures markets, and investors demonstrate the flight-to-quality phenomenon during financial crises. 
More recently, authors have focused their attention on modeling and forecasting the VaR of precious metals. For example, Hammoudeh, Araújo Santos, and Al-Hassan (2013) suggested that an optimal portfolio should consist of more gold than any other asset class. Furthermore, gold plays an important role in VaR-based optimal, efficient and diversified portfolio construction. Demiralay and Ulusoy (2014) found that VaR analysis for long and short trading positions of precious metals perform well under long-memory volatility models with Student's t-distribution. However, the FIAPARCH model with Student's tdistribution was found to perform well in one-day ahead VaR predictions. Zhang and Zhang (2016) reported that gold outperforms other precious metals and has the highest $\mathrm{VaR}$. The authors reported palladium to have the most volatile VaR among precious metals.

The hedging properties of precious metals have also been studied extensively. For example, Pierdzioch, Risse and Rohloff (2016) reported that precious metals, particularly gold and silver, provide suitable hedging against adverse movements in major exchange rates. Bredina, Conlon and Potì (2017) investigated the role of precious metals in downside risk reduction and argued that gold, silver and platinum reduce risk in the short term but argued against the use of silver and platinum in the long term. McCown and Shaw (2016) suggested the use of platinum over gold as a safe-haven during a period of shocks. However, McCown and Shaw (2016) did not find the same hedging capabilities for palladium and rhodium.

Hence, it is evident that, although several studies investigate the dynamics among precious metals, the causality among precious metals has not been consistently described in these studies, which serves as a motivation to undertake this study.

\section{Data}

The analysis is conducted on the daily data (4320 observations) of spot prices of four precious metals: (a) Gold, (b) Silver, (c) Platinum and (d) Palladium; this analysis spans the period April 1, 2000 to July 25, 2016. For robustness check, a replication of the study was performed on weekly data (865 observations) for the same time-period. All the data were extracted from the Bloomberg database. The price returns are calculated for the variables with consideration to the differences between natural $\operatorname{logs}$, i.e., $R_{t}=\ln \left(\begin{array}{ll}P_{t} & P_{t 1}\end{array}\right)$.

Table 1 (a) and (b) show the descriptive statistics of daily and weekly data, respectively. The stochastic properties of the data reveal that gold yields the highest mean returns. Palladium exhibits the most volatile behavior in terms of highest value of standard deviation. The skewness coefficient for all the metals is negative, which shows more frequent occurrences of negative returns. The investor community often appreciates a significant and positive kurtosis coefficient, the underlying reason being a higher probability of positive returns. The Jarque-Bera test depicts the non-normality in the data, and the Ljung-Box test at lag 10 shows serial dependence for Palladium for daily and Platinum for weekly data, respectively. In addition, the gold-silver correlation is found to be the strongest. On the other hand, the gold-palladium correlation is the weakest. 
Table 1. Descriptive Statistics

(a) Daily Data

\begin{tabular}{lcccc}
\hline & Gold & Silver & Palladium & Platinum \\
\cline { 2 - 5 } Minimum & -9.810 & -19.489 & -13.367 & -9.603 \\
Maximum & 8.625 & 12.196 & 15.260 & 10.375 \\
Mean & 0.036 & 0.030 & 0.010 & 0.022 \\
Standard Deviation & 1.145 & 1.981 & 2.096 & 1.457 \\
Skewness & -0.241 & -0.892 & -0.285 & -0.471 \\
Kurtosis $_{\text {Jarque-Bera a }}{ }^{2}$ & 8.545 & 10.823 & 7.248 & 7.466 \\
Ljung-Box Q-Stat. (10) $^{\mathrm{b}}$ & 342.19 & 593.57 & 312.02 & 175.04 \\
& 14.04 & 3.51 & 45.24 & 15.57 \\
Unconditional Correlations $^{\mathrm{c}}$ & $(0.17)$ & $(0.97)$ & $(0.00)$ & $(0.11)$ \\
Gold $_{\text {Silver }}$ & 1 & & & \\
Palladium & $0.771^{* *}$ & 1 & & \\
Platinum & $0.410^{* *}$ & $0.483^{* *}$ & 1 & \\
\hline
\end{tabular}

Note: ${ }^{\text {a }}$ The critical value of the Jarque-Bera test at the 5\% level is 5.99 .

${ }^{\mathrm{b}}$ The Ljung-Box test was performed using a lag of 10 . The $\mathrm{p}$-values are reported in parentheses. $\mathrm{c} * *$ Correlations are significant at the $1 \%$ level (2-tailed)

(b) Weekly Data

\begin{tabular}{lcccc}
\hline & Gold & Silver & Palladium & Platinum \\
\cline { 2 - 5 } Minimum & -10.135 & -31.989 & -21.357 & -15.164 \\
Maximum & 12.346 & 14.620 & 17.641 & 11.344 \\
Mean & 0.178 & 0.154 & 0.050 & 0.117 \\
Standard Deviation & 2.528 & 4.407 & 4.887 & 3.227 \\
Skewness $_{\text {Kurtosis }}$ & -0.251 & -1.288 & -0.347 & -0.571 \\
Jarque-Bera $^{\text {a }}$ & 4.651 & 10.113 & 4.867 & 5.367 \\
Ljung-Box Q-Stat. (10) $^{\mathrm{b}}$ & 68.32 & 120.99 & 62.28 & 34.66 \\
Unconditional Correlations $^{\mathrm{c}}$ & 11.69 & 11.81 & 17.45 & 20.64 \\
Gold $_{\text {Silver }}$ & $(0.31)$ & $(0.30)$ & $(0.07)$ & $(0.02)$ \\
Palladium $_{\text {Platinum }}$ & 1 & & & \\
\hline
\end{tabular}

Note: ${ }^{\text {a }}$ The critical value of the Jarque-Bera test at the $5 \%$ level is 5.99 .

${ }^{\mathrm{b}}$ The Ljung-Box test was performed using a lag of 10 . The $\mathrm{p}$-values are reported in parentheses.

$\mathrm{c} * *$ Correlations are significant at the $1 \%$ level (2-tailed) 


\section{Estimation Methodology}

This section briefly describes the methodology adopted to investigate the causality among prices of precious metals. For a robust approximation of causality, the nonlinear method of Balcilar et al. (2016a) ${ }^{1}$ is applied, which endows at least a couple of benefits over the traditional techniques, namely: (a) minimization of misspecification error probabilities as the dependence structure is estimated using a nonparametric procedure and (b) higher order dependencies (mean and variance) could be detected using this technique. Thus, it becomes possible to derive additional information related to dependence structure, which traditional techniques may fail to capture. In other words, causality tests that are conditional upon mean values may have limited ability to reflect the true dependence structure. The quantile causality approach of Balcilar et al. (2016a), closely follows the frameworks suggested by Nishiyama et al. (2011) and Jeong et al. (2012) and is described as follows.

The nonlinear causality in one precious metal, $y(t)$, is examined with the predictor precious metal, $x(t)$, and then the quantile causality is tested in reverse order. Following Jeong et al., (2012), the quantile-based causality may be defined as:

With respect to a lag vector $\left\{y_{t}, \ldots, y_{t p}, x_{t 1}, \ldots, x_{t p}\right\}, x(t)$ does not cause $y(t)$ in the th quantile if

$$
Q\left(y_{t} \mid y_{t 1}, \ldots, y_{t p}, x_{t 1}, \ldots, x_{t p}\right)=Q\left(y_{t} \mid y_{t 1}, \ldots, y_{t p}\right)
$$

and further, $x(t)$ may be assumed to cause $y(t)$ in the th quantile respective to $\left\{y_{t 1}, \ldots, y_{t p}, x_{t 1}, \ldots, x_{t p}\right\}$ if

$$
Q\left(y_{t} \mid y_{t 1}, \ldots, y_{t p}, x_{t 1}, \ldots, x_{t p}\right) \quad Q\left(y_{t} \mid y_{t 1}, \ldots, y_{t p}\right)
$$

where $Q\left(y_{t} \mid.\right)$ is the th quantile of $y(t)$. The conditional quantiles of $y(t), Q\left(y_{t} \mid.\right)$ depend on $t$ and the quantiles are restricted between zero and one, i.e., $0 \pi \theta \pi 1$.

The implication of the causality in mean from $x(t)$ to $y(t)$ in the th quantile is that the historical values of $x(t)$ may assist to predict the values of $y(t)$ in th quantile, but not in other quantiles. As stated earlier, this test is an extension of Jeong et al., (2012) to test for the second moment. Besides, while testing the causality in the higher order moments, a common complication, which arises, is the $k^{\text {th }}$ moment, which usually implies causality in the $m^{\text {th }}$ moment for $k \pi m$. The causality-in-quantile method applies a sequential nonparametric Granger quantile causality approach of Nishiyama et al., (2011) to eliminate the stated complication.

\footnotetext{
${ }^{1}$ This paper briefly describes the causality-in-quantile methodology. For a detailed description, refer to (Balcilar et al., 2016a, 2016b).
} 
To justify the application of the causality-in-quantiles test, the stochastic behavior of the variables under consideration was examined. The phenomenon of non-linearity in an economic time-series has been widely recognized by scholars in the past (Tsay, 1986). To test for nonlinearity in the data, the BDS test proposed by Broock et al. (1996) was employed on the residuals of the AR(1) model. Table 2 exhibits the test statistics for the BDS test; the results clearly reject the null hypothesis that the variables of interest are independently and identically distributed (iid) (across various dimensions and at 1 percent level of significance). Hence, the phenomenon of nonlinearity in the dataset is strongly evident. Furthermore, the Bai and Perron's (2003) multiple structural break test was applied. Structural breaks were found to exist in the data (Table 3 exhibits the structural break dates).

Table 2. BDS Test (Broock et al., 1996)

\begin{tabular}{|c|c|c|c|c|c|}
\hline & \multicolumn{5}{|c|}{ Dimension } \\
\hline & 2 & 3 & 4 & 5 & 6 \\
\hline \multicolumn{6}{|l|}{ Daily Data } \\
\hline$A R(1):$ Gold & $2.27 * * *$ & $3.87 * * *$ & $5.30 * * *$ & $6.12 * * *$ & $7.43 * * *$ \\
\hline$A R(1)$ : Silver & $7.95 * * *$ & $11.09 * * *$ & $14.04 * * *$ & $16.85 * * *$ & $20.49 * * *$ \\
\hline$A R(1)$ : Palladium & $11.03 * * *$ & $14.90 * * *$ & $18.07 * * *$ & $21.13 * * *$ & $25.38 * * *$ \\
\hline$A R(1)$ : Platinum & $9.48 * * *$ & $12.15 * * *$ & $14.20 * * *$ & $15.66 * * *$ & $18.07 * * *$ \\
\hline \multicolumn{6}{|l|}{ Weekly Data } \\
\hline$A R(1):$ Gold & $3.19 * * *$ & $2.76 * * *$ & $3.82 * * *$ & $5.31 * * *$ & $6.31 * * *$ \\
\hline$A R(1)$ : Silver & $2.33 * * *$ & $3.89 * * *$ & $5.75 * * *$ & $7.72 * * *$ & $9.77 * * *$ \\
\hline$A R(1):$ Palladium & $5.29 * * *$ & $5.70 * * *$ & $6.21 * * *$ & $6.57 * * *$ & $7.38 * * *$ \\
\hline$A R(1)$ : Platinum & $5.74 * * *$ & $5.46 * * *$ & $5.57 * * *$ & $5.49 * * *$ & $5.22 * * *$ \\
\hline
\end{tabular}

Table 3. Bai and Perron's Multiple Structural Break Test

\begin{tabular}{lllll}
\hline Models & Break Dates & & & \\
\hline$A R(1):$ Gold & $2003 / 04 / 03 ;$ & $2006 / 05 / 09 ;$ & $2008 / 11 / 11 ;$ & $2011 / 08 / 05 ;$ \\
& $2014 / 01 / 28$ & & & \\
$A R(1):$ Silver & $2003 / 06 / 25 ;$ & $2006 / 04 / 17 ;$ & $2008 / 10 / 24 ;$ & $2011 / 04 / 27 ;$ \\
& $2013 / 11 / 29$ & & & \\
$A R(1):$ Palladium & $2003 / 04 / 15 ;$ & $2006 / 05 / 09 ;$ & $2008 / 12 / 03 ;$ & $2011 / 06 / 07 ;$ \\
& $2013 / 12 / 19$ & & \\
$A R(1):$ Platinum & $2002 / 07 / 19 ;$ & $2006 / 05 / 18 ;$ & $2008 / 12 / 03 ;$ & $2011 / 06 / 07 ;$ \\
& $2013 / 12 / 17$ & & & \\
\hline
\end{tabular}

Note: Dates are in the YYYY:MM:DD format

The presence of nonlinearity and multiple structural breaks in the data leads the linear Granger causality tests to be susceptible to misspecification, and thus, they cannot be relied 
upon (Babalos and Balcilar, 2016; Bekiros et al., 2016) ${ }^{2}$. However, to facilitate comparability, we also employed a standard linear Granger causality test with VAR (1) model specification. Table 4 and Table 5 show the linear Granger causality tests for daily and weekly data, both in pairs and in groups. Table 4 shows evidence of gold significantly causing movements for silver and palladium. Furthermore, gold also causes movements in other precious metal groups. However, the other causal relationships were found to be insignificant under the assumption of linearity. Further, the linear Granger causality test is insignificant for all pairs and groups in weekly data (Table 5). As noted earlier, the linear Granger causality test suffers certain limitations when used for nonlinear data. Thus, the nonparametric causality-in-quantiles test is used.

Table 4. Linear VAR (1) Granger Causality Test for Daily Data

\begin{tabular}{lcc}
\hline \multicolumn{1}{c}{ Granger Causality } & & \\
\hline Null Hypothesis & $\boldsymbol{F}$-Stat & P-Value \\
\hline Gold $\neq \phi$ Silver & 6.16 & 0.00 \\
Silver $\neq \phi$ Gold & 2.03 & 0.13 \\
Gold $\neq \phi$ Palladium & 6.53 & 0.00 \\
Palladium $\neq \phi$ Gold & 1.15 & 0.31 \\
Gold $\neq \phi$ Platinum & 2.22 & 0.11 \\
Platinum $\neq \phi$ Gold & 0.24 & 0.79 \\
Silver $\neq \phi$ Palladium & 1.27 & 0.28 \\
Palladium $\neq \phi$ Silver & 0.83 & 0.44 \\
Silver $\neq \phi$ Platinum & 0.14 & 0.87 \\
Platinum $\neq \phi$ Silver & 0.80 & 0.45 \\
Palladium $\neq \phi$ Platinum & 1.32 & 0.27 \\
Platinum $\neq \phi$ Palladium & 0.24 & 0.79 \\
\hline Gold $\neq \phi$ Silver, Palladium, Platinum & 3.79 & 0.00 \\
Silver $\neq \phi$ Gold, Palladium, Platinum & 1.22 & 0.29 \\
Palladium $\neq \phi$ Gold, Silver, Platinum & 1.24 & 0.28 \\
Platinum $\neq \phi$ Gold, Silver, Palladium & 1.36 & 0.27 \\
\hline
\end{tabular}
$\neq \phi$ : represents "do not Granger cause"

\footnotetext{
${ }^{2}$ It is important to note that our results are subject to modelling assumptions. For example, separability which implies that all observationally identical agents face the same marginal effect. It's difficult to justify empirically in many situations and also to justify with economic theory. We thank an anonymous referee for pointing out this fact.
} 
Table 5. Linear VAR (1) Granger Causality Test for Weekly Data

\begin{tabular}{lcc}
\hline \multicolumn{1}{c}{ Granger Causality } & & \\
\hline Null Hypothesis & F-Stat & P-Value \\
\hline Gold $\neq \phi$ Silver & 1.46 & 0.23 \\
Silver $\neq \phi$ Gold & 0.03 & 0.97 \\
Gold $\neq \phi$ Palladium & 1.78 & 0.17 \\
Palladium $\neq \phi$ Gold & 1.07 & 0.34 \\
Gold $\neq \phi$ Platinum & 0.15 & 0.86 \\
Platinum $\neq \phi$ Gold & 0.10 & 0.90 \\
Silver $\neq \phi$ Palladium & 0.75 & 0.47 \\
Palladium $\neq \phi$ Silver & 0.24 & 0.79 \\
Silver $\neq \phi$ Platinum & 0.03 & 0.96 \\
Platinum $\neq \phi$ Silver & 0.99 & 0.37 \\
Palladium $\neq \phi$ Platinum & 2.19 & 0.11 \\
Platinum $\neq \phi$ Palladium & 0.23 & 0.79 \\
\hline Gold $\neq \phi$ Silver, Palladium, Platinum & 1.18 & 0.32 \\
Silver $\neq \phi$ Gold, Palladium, Platinum & 0.56 & 0.76 \\
Palladium $\neq \phi$ Gold, Silver, Platinum & 1.69 & 0.12 \\
Platinum $\neq \phi$ Gold, Silver, Palladium & 0.81 & 0.56 \\
\hline
\end{tabular}

$\neq \phi$ : stands for "do not Granger cause"

\section{Empirical Results}

This section presents the results of quantile causality tests among the prices of precious metals. The difference between linear Granger causality and the nonparametric causalityin-quantiles approach is that the latter considers all the quantiles in the distribution, whereas the former considers only the center of the distribution. Therefore, this approach can show how causality behaves in low and high precious metal returns. Moreover, causality-in-quantiles allows analysis of the causality in mean and variance.

Figure 1 and Figure 2 show the results of quantile causality tests among the prices of precious metals in mean and variance, respectively, for daily data. The vertical axis shows the non-parametric quantile causality test statistics against the corresponding quantiles in the horizontal axis. The horizontal solid line shows a value of 1.95 and corresponds to a critical value at the $5 \%$ level of significance. The null hypothesis states that a change in the price of a given precious metal does not Granger-cause a change in the price of the other precious metal. For example, the causality test in mean for gold to silver in Figure 1 indicates the null hypothesis that gold does not Granger-cause silver is rejected $(\mathrm{p}<0.05)$ over the quantile range of $0.28-0.45$ and $0.65-0.75$. Except for gold to silver, gold to platinum and platinum to gold, the causality in the quantile test rejects the null hypothesis over the quantile range of 0.25 to 0.75 . The quantile range for other causality tests in mean are well beyond 0.25 to 0.75 . For the causality test in mean from silver to gold, the range is $0.10-0.80$; for silver to platinum, the range is $0.20-0.75$. For silver to palladium, the range is $0.20-0.80$; for platinum to silver, the range is $0.25-0.85$. For platinum to palladium, the range is $0.23-0.85$; for palladium to gold, the range is $0.18-0.85$. For palladium to silver 
the range is $0.20-0.85$; for palladium to platinum, the range is $0.18-0.80$. Overall, precious metals exhibit weak predictive powers in extreme ranges and strong predictive power over middle quantiles.

Figure 2 shows the quantile causality among precious metals in variance (second moment) for daily data. The differences between the quantile causality in mean and variance are somewhat noteworthy. Causality in variance from gold to other precious metals is not very different from causality in mean from gold to other precious metals. The results also indicate causality in variance from silver to gold in middle quantiles but no causality in variance from silver to platinum and palladium. There is strong evidence of causality in platinum to other precious metals over all the quantiles and weak evidence of causality from palladium to other precious metals. The difference in the causality in variance and causality in mean indicates that causality from one precious metal to another varies in the first and second moments. This capability of quantile casualty provides additional information regarding the relationship among precious metals. For example, there is very strong causality in variance from platinum to other metals in comparison to causality in mean from platinum to other metals. Furthermore, the hump shape pattern of causality indicates the advantage of using the quantile causality approach over studies that use only median values. Such studies may find evidence of causality but, even then, would miss the evidence of causality over other quantiles.

Linear causality suggested only one-way causality from gold to silver and palladium (Table 4). In comparison to linear Granger causality, quantile causality provides several interesting findings. First, quantile causality provides evidence of causality among precious metals. Causality not only exists in the case of gold to silver and gold to palladium, but we found overwhelming evidence of bivariate quantile causality in mean for all the precious metals (see Figure 1).

Second, the variation in causality may be overlooked in linear causality analysis and quantile causality provides additional information about causality patterns. For example, causality in mean is stronger in the case of silver to gold than causality from gold to silver. In comparison to causality from gold to platinum, causality from platinum to gold also exists in lower quantiles. Regarding causality between gold and palladium, causality from palladium to gold exists over extra quantiles.

Third, quantile causality also provides evidence of causality in variance. We found bivariate quantile causality in variance for almost all the precious metals except for palladium to gold, silver to platinum, silver to palladium and palladium to silver. The bivariate causality in variance between gold and silver exists for middle quantiles only. For gold to platinum the causality relationship exists for a very small range; however, platinum to gold exhibits strong causality over all the quantiles. Platinum and palladium also show bidirectional causality but causality from palladium to platinum exists over a very small range. Further, there exists only one-way causality from gold to palladium, and platinum to silver. Causality from platinum to other precious metals in variance shows a very strong influence of the volatility of platinum on other precious metals. ${ }^{3}$ One of the logical

\footnotetext{
${ }^{3} \mathrm{We}$ are thankful to the anonymous reviewer for highlighting this point.
} 
attributions could be the fact that platinum is very expensive in comparison to gold, silver and palladium and any variation in platinum prices has repercussions on the demand for other precious metals and, eventually, on their prices. Additionally, platinum is an essential raw material in the automobile industry as well as being used extensively in the jewelry industry and portfolio balancing. Any variation in demand for platinum in the automobile industry would have an impact on platinum prices and, as a result, the volatility gets transferred to precious metal markets.

Our results provide evidence against the notion and evidence from linear models that gold causes changes in all the metals but not vice versa. Causality is not a static phenomenon but varies with the market state (boom, recession and normal time-period). Moreover, precious metals exhibit weak predictive powers in extreme ranges and strong predictive power over middle quantiles. Therefore, our results suggest that precious metals have strong predictive powers during normal time periods and weak or no causality in lower (bearish market) or upper (bullish market) quantiles. Our results for middle quantiles (normal period) support the findings of Sensoy (2013) that precious metals converge to a single asset class. Further, the strong causality in middle quantiles suggest against diversification benefits during normal time periods but, on the other hand, suggests above normal diversification benefits during periods of boom and recession. It further suggests that precious metals could be used as hedging instruments against each other during periods of uncertainty or extreme low prices and during periods of economic growth or extreme high prices.

The results also have economic implications for policy makers, investors and portfolio managers as they relate particularly to price forecasting and the dependence structure of precious metal returns and volatility. The finding that precious metal prices tend to move together during normal time periods suggests investors should invest in different asset classes to achieve diversification benefits. However, the low or absent causality at extreme tails can be good news to investors and portfolio managers to devise investment strategies accordingly.

In the volatility causality context, the findings suggest that volatility in the price of one precious metal impacts the prices of other precious metals. However, results show that causality in variance from platinum to other precious metals requires maximum attention. Nevertheless, these results have important implications for policy makers who are concerned regarding the stability of commodity markets. If extreme volatility movements in precious metals can be predicted by volatility movements in one precious metal, as the results indicate, such information can be used for monitoring and modeling volatility shocks in the precious metal market and, consequently, effective strategies can be designed to moderate the impact of volatility shocks.

\section{Robustness Test}

To check the robustness of our findings, the quantile causality technique was employed on weekly spot prices of precious metals. Figure 3 and Figure 4 show the quantile causality results for weekly data in mean and variance respectively. While comparing the results of 
quantile causality with linear Granger causality for weekly data (Table 5) it can be noticed that linear causality was not able to account for any causality among precious metals. However, quantile causality results indicate a strong causality pattern in volatility. Therefore, quantile causality can extract causality in variance, even if there is no causality or weak causality in variance. These results, on the one hand, suggest that the average daily prices of precious metals have a strong influence on each other's prices in comparison to average weekly prices. On the other hand, the variation in weekly prices has a greater influence among precious metal prices than do the daily price variations. These findings further strengthen our approach of using quantile causality to analyze the relationship among precious metals. Finally, the present study may be extended in following two ways: (1) exploring the relationship by using some time varying or non-linear estimations which allows for nonlinearity in parameters; (2) explore the possible lead-lag relationship between the variance of one commodity and returns of another commodity. 

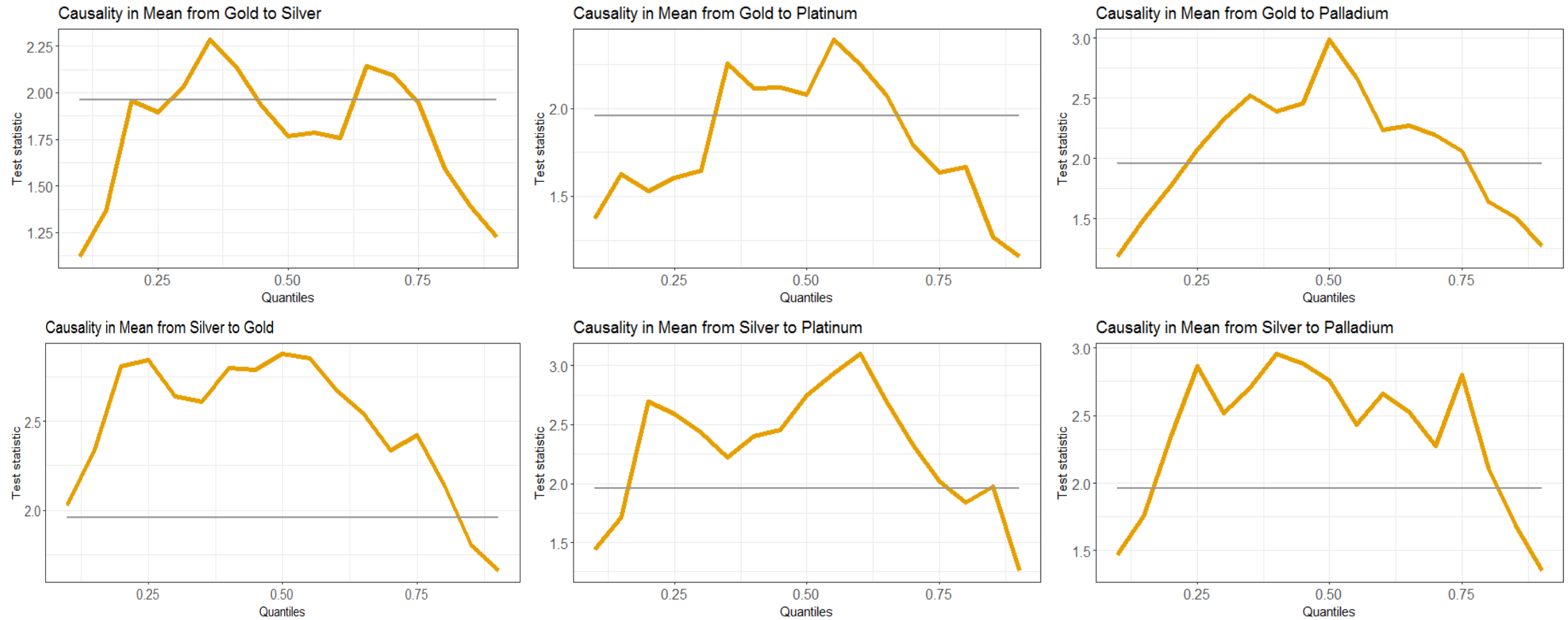

Causality in Mean from Silver to Palladium
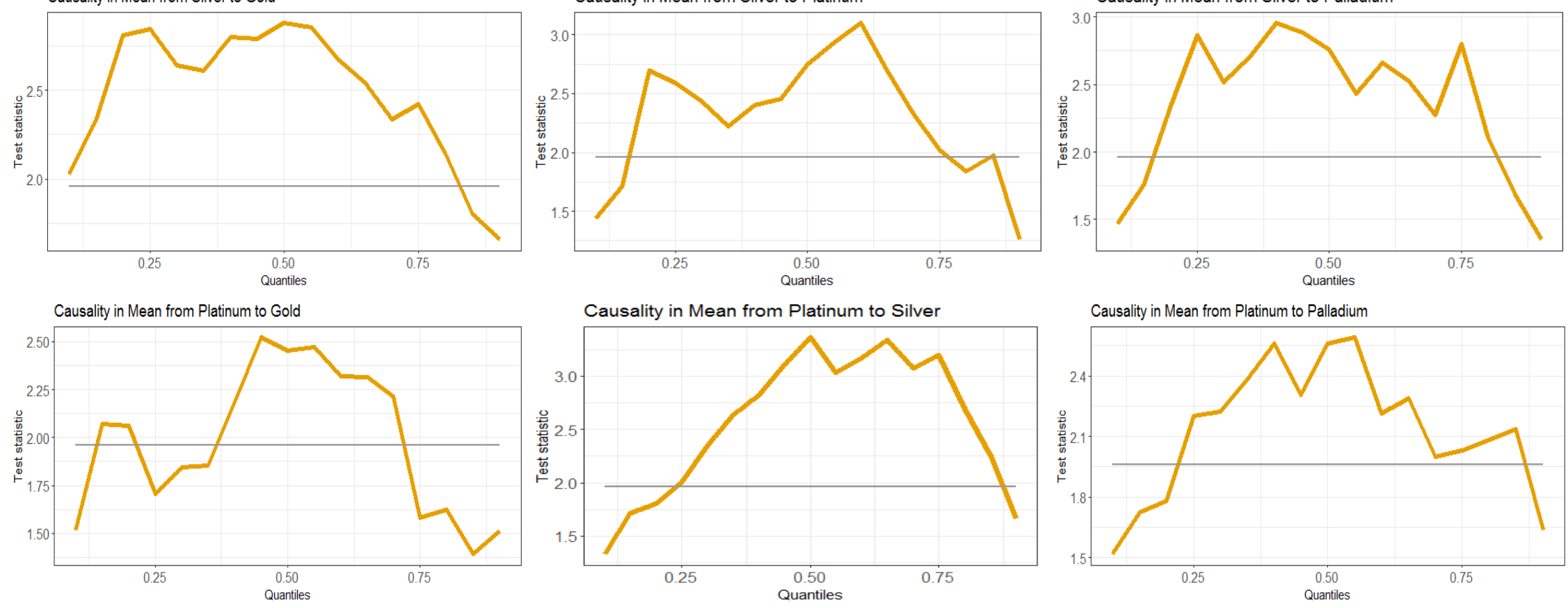

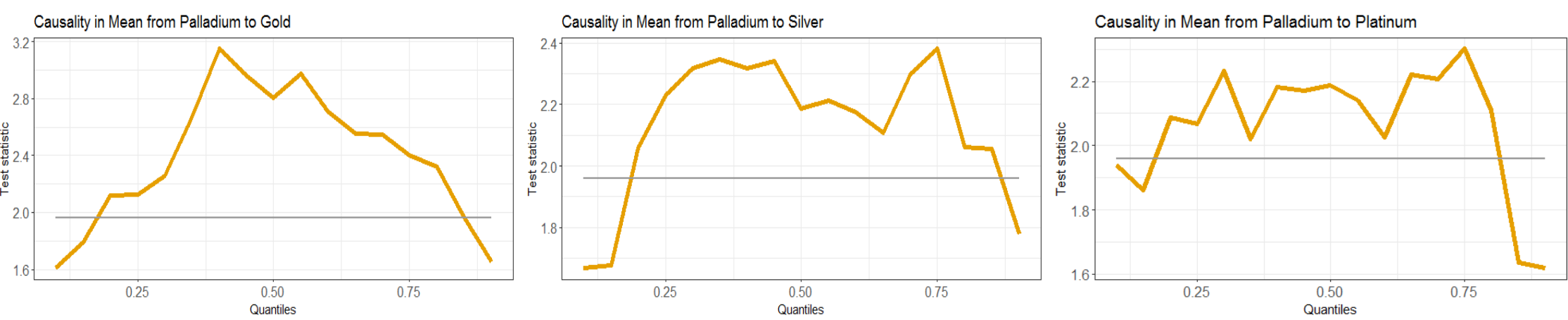

Figure 1. Causality in mean between precious metals (daily data)

Note: This figure shows the causality results from one precious metal to another in mean. The null hypothesis states that a change in the price of a given precious metal does not Granger-cause a change in the price of the other precious metal as judged by the mean price. For example, the top left graph shows the causality in mean from gold to silver, which means the quantile causality results for the null hypothesis that gold does not Granger-cause silver in mean. The vertical axis shows the non-parametric quantile causality test statistics against the corresponding quantiles in the horizontal axis. The horizontal solid line shows a value of 1.95 and corresponds to a critical value at the $5 \%$ level of significance. 

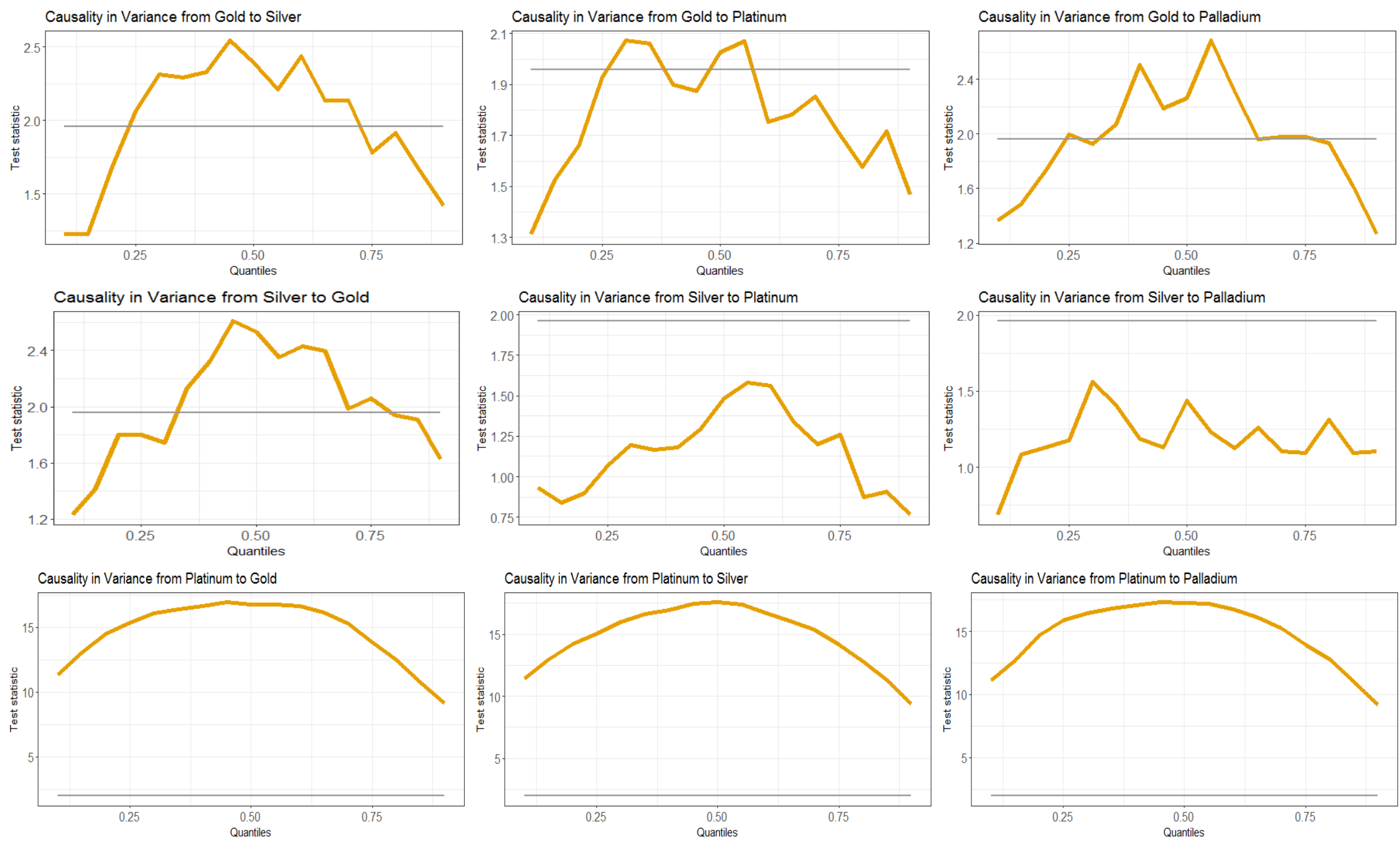

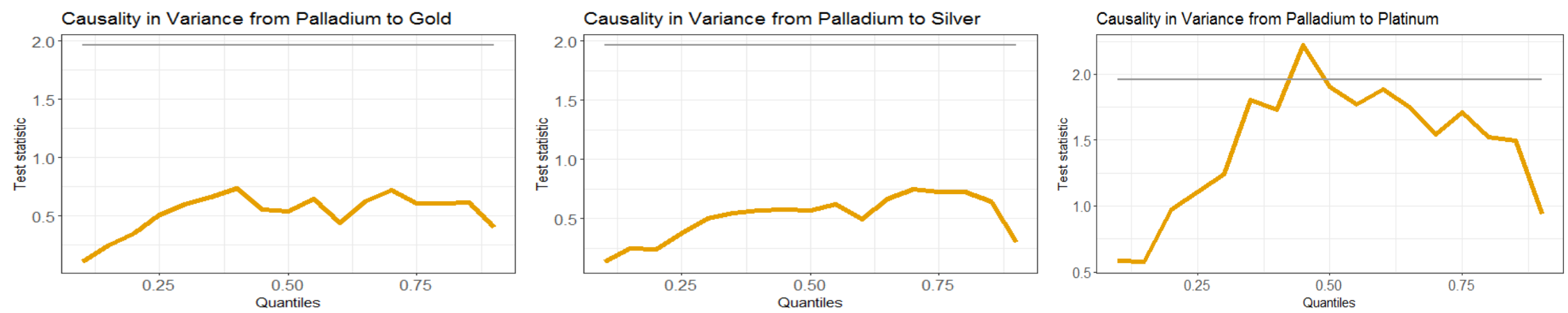

Figure 2. Causality in variance between precious metals (daily data)

Note: This figure shows the causality results from one precious metal to another in variance. The null hypothesis states that a change in the price of a given precious metal does not Granger-cause a change in the price of the other precious metal as judged by variance. For example, the top left graph shows the causality in variance from gold to silver, which means the quantile causality results for the null hypothesis that gold does not Granger-cause silver in variance. The vertical axis shows the non-parametric quantile causality test statistics against the corresponding quantiles in the horizontal axis. The horizontal solid line shows a value of 1.95 and corresponds to a critical value at the $5 \%$ level of significance. 

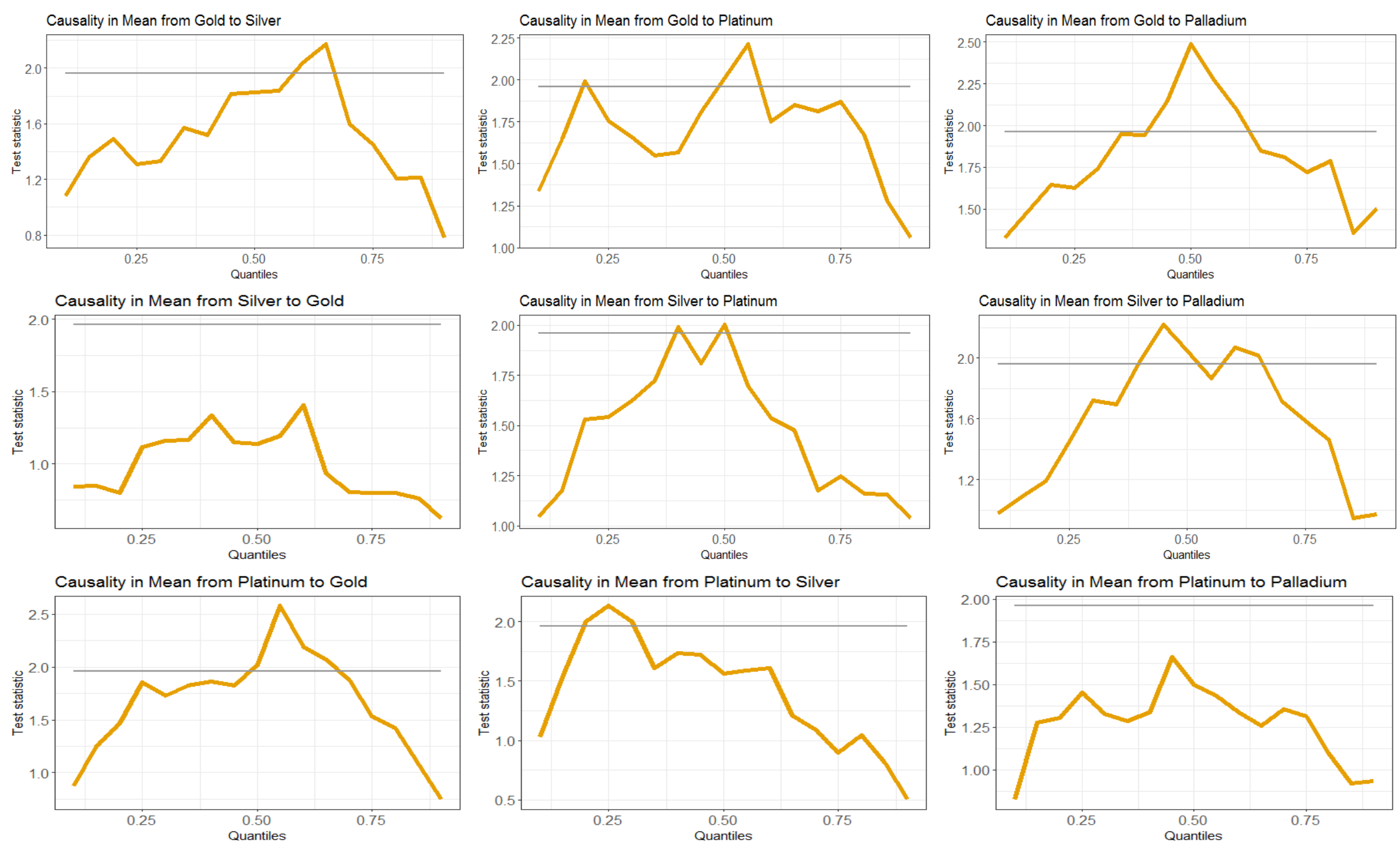

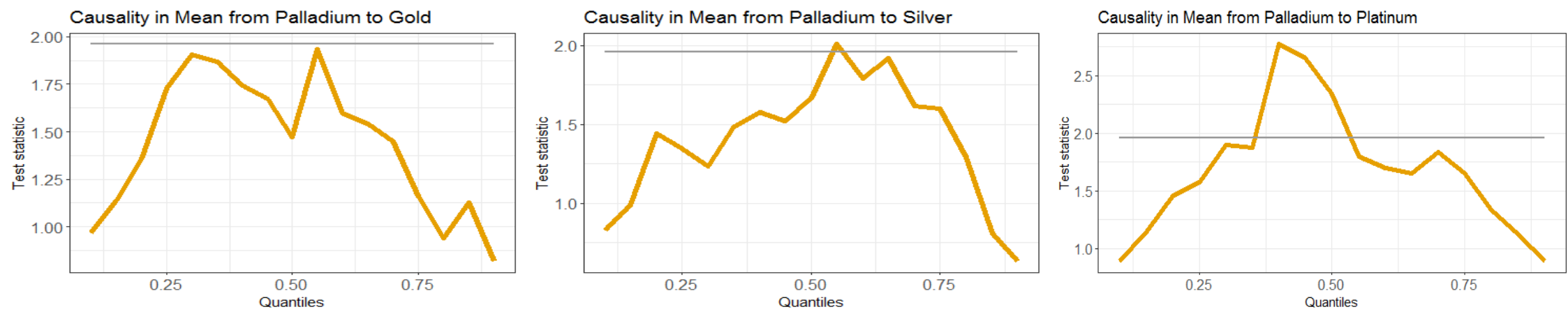

Figure 3. Causality in mean between precious metals (weekly data)

Note: This figure shows the causality results from one precious metal to another in mean. The null hypothesis states that a change in the price of a given precious metal does not Granger-cause a change in the price of the other precious metal as judged by the mean. For example, the top left graph shows the causality in mean from gold to silver which means the quantile causality results for the null hypothesis that gold does not Granger-cause silver in mean. The vertical axis shows the non-parametric quantile causality test statistics against the corresponding quantiles in the horizontal axis. The horizontal solid line shows a value of 1.95 and corresponds to a critical value at the $5 \%$ level of significance. 

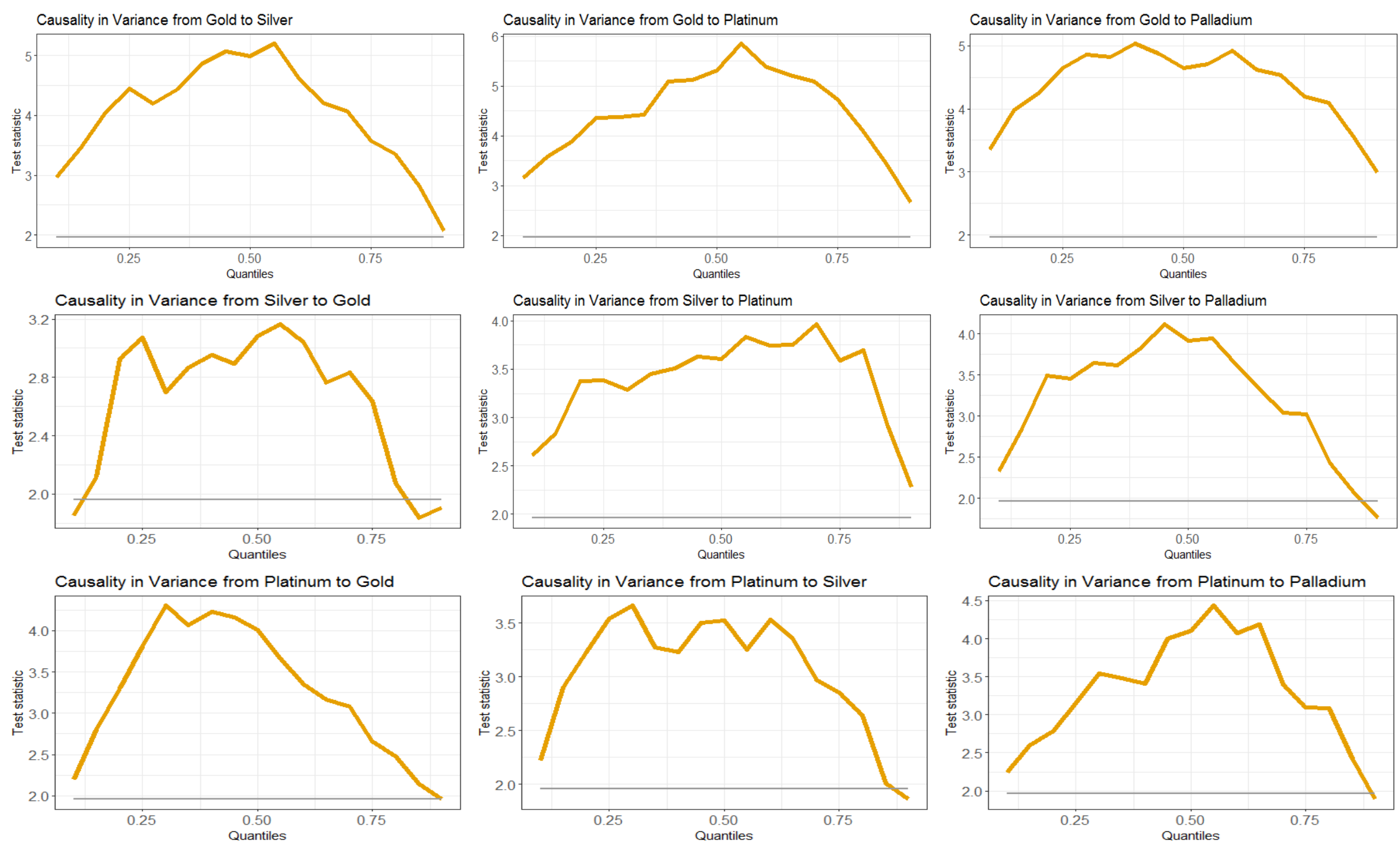

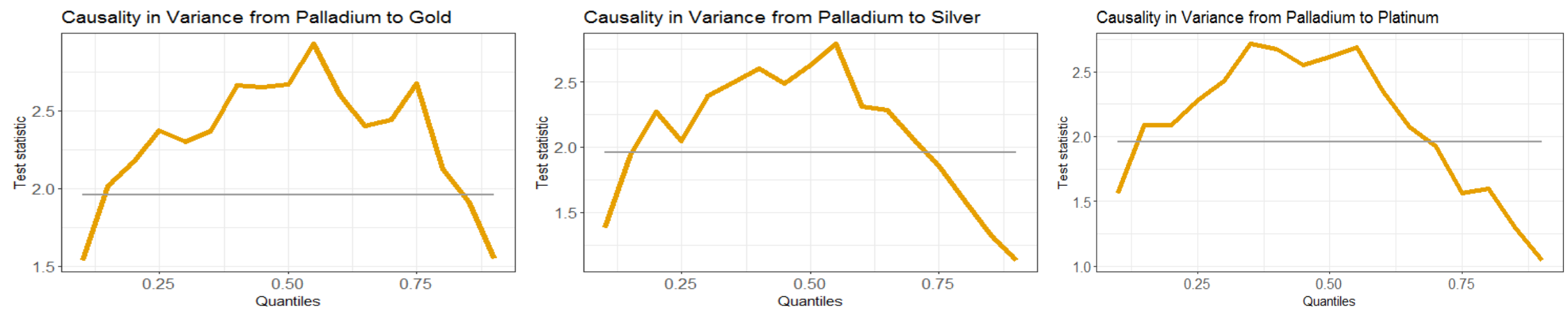

Figure 4. Causality in variance between precious metals (weekly data)

Note: This figure shows the causality results from one precious metal to another in variance. The null hypothesis states that a change in the price of a given precious metal does not Granger-cause a change in the price of the other precious metal as judged by variance. For example, the top left graph shows the causality in variance from gold to silver, which means the quantile causality results for the null hypothesis that gold does not Granger-cause silver in variance. The vertical axis shows the non-parametric quantile causality test statistics against the corresponding quantiles in the horizontal axis. The horizontal solid line shows a value of 1.95 and corresponds to a critical value at the $5 \%$ level of significance. 


\section{Conclusions}

We investigate the causality among precious metal prices by taking daily values for the period of April 2000 to July 2016. To analyze the robustness of our results, the relationship under a different time horizon, i.e., weekly data, was also analyzed to substantiate the claims of causality among precious metal prices. The whole empirical investigation was conducted in four steps. First, we checked for non-linearity and structural breaks in the data, which suggested the presence of both features and therefore indicated the usage of non-linear techniques for further analysis. In the second step, to facilitate the comparison of results between linear and non-linear techniques on the data with non-linear properties, linear Granger causality was employed. In the third step we employed the nonparametric quantile causality test suggested by Balcilar et al. (2016a). This technique also enabled us to examine precious metal causality in mean and variance. Fourth, to check the robustness of our results we employed the quantile causality test on weekly data.

In contrast to Sensoy (2013), our results indicate the existence of two-way causality among precious metals. However, the extent of causality differs in mean and variance. Furthermore, the causality among precious metals in mean and variance also differs for daily and weekly metal prices. Overall, we find that the average daily prices of precious metals have a strong influence on each other in comparison to average weekly prices. However, the variation in weekly prices has a greater influence among precious metal prices than do daily price variations. Thus, the quantile causality offers a unique advantage of analyzing the causality in variance, although results indicate weak or no causality in mean. These results highlight the significance of modeling nonlinearity in examining the causal relationship.

Our results have important implications for investors, portfolio managers and policy makers. Precious metals tend to behave as a single asset class during normal time periods but move independently during crisis and boom periods. Therefore, our results suggest possible diversification benefits among precious metals during stressful periods such as an economic crisis. In other words, the hump-shaped pattern in our results indicates that a measure of uncertainty exhibits strong causality at the middle of the conditional distribution among precious metals. However, investors and policy makers should analyze the entire conditional distribution of precious metal movements when investigating the impact of economic and political uncertainty, such as in financial crises or other economic events. The asymmetric hump shape patterns also suggest a difference between the strength (significance) of relationships across different parts of the conditional distribution of precious metal prices. More specifically, these results have implications for countries which depend on imports to meet the domestic demand of precious metals and, therefore, can come under enormous strain to manage trade balances.

Finally, our empirical analysis provides several possible future research directions. One interesting future study could be to include several time horizons to analyze the causality among precious metals. Our study provides evidence of causality only for daily and weekly precious metal returns. To include high-frequency data and longer time horizons (e.g., monthly, quarterly, semi-annually) can greatly improve our understanding of dynamics 
among precious metals. Secondly, the scope of the present study can be improved by including other precious metals so that their influence can also be investigated under a nonlinear setup.

\section{Acknowledgements}

We are thankful to Dr. Gary Campbell, Editor, Resources Policy for the opportunity to improvise our work. We are also indebted to the anonymous reviewers for their insightful comments.

\section{References}

Agyei-Ampomah, S., Gounopoulos, D., Mazouz, K., 2014. Does gold offer a better protection against losses in sovereign debt bonds than other metals? J. Bank. Financ. 40, 507-521.

Antonakakis, N., Kizys, R., 2015. Dynamic spillovers between commodity and currency markets. Int. Rev. Financ. Anal. 41, 303-319.

Arouri, M.E.H., Hammoudeh, S., Lahiani, A., Nguyen, D.K., 2012. Long memory and structural breaks in modeling the return and volatility dynamics of precious metals. Q. Rev. Econ. Financ. 52, 207-218.

Babalos, V., Balcilar, M., 2016. Does institutional trading drive commodities prices away from their fundamentals: Evidence from a nonparametric causality-in-quantiles test. Financ. Res. Lett.

Bai, J., Perron, P., 2003. Computation and analysis of multiple structural change models. J. Appl. Econom. 18, 1-22.

Balcilar, M., Bekiros, S., Gupta, R., 2016a. The role of news-based uncertainty indices in predicting oil markets: a hybrid nonparametric quantile causality method. Empir. Econ. 1-11. doi:https://doi.org/10.1007/s00181-016-1150-0

Balcilar, M., Gupta, R., Pierdzioch, C., 2016b. Does uncertainty move the gold price? New evidence from a nonparametric causality-in-quantiles test. Resour. Policy 49, 74-80.

Batten, J.A., Ciner, C., Lucey, B.M., 2010. The macroeconomic determinants of volatility in precious metals markets. Resour. Policy 35, 65-71.

Baur, D.G., 2012. Asymmetric volatility in the gold market. J. Altern. Investments 14, $26-38$.

Baur, D.G., Lucey, B.M., 2010. Is Gold a Hedge or a Safe Haven? An Analysis of Stocks, Bonds and Gold. Financ. Rev. 45, 217-229. doi:10.1111/j.15406288.2010.00244.x

Baur, D.G., McDermott, T.K., 2010. Is gold a safe haven? International evidence. J. Bank. Financ. 34, 1886-1898. doi:10.1016/j.jbankfin.2009.12.008

Baur, D.G., Tran, D.T., 2014. The long-run relationship of gold and silver and the influence of bubbles and financial crises. Empir. Econ. 47, 1525-1541.

Bekiros, S., Gupta, R., Kyei, C., 2016. On economic uncertainty, stock market predictability and nonlinear spillover effects. North Am. J. Econ. Financ. 36, 184191. doi:10.1016/j.najef.2016.01.003

Bredina, D., Conlon, T., Potì, V., 2017. The Price of Shelter-Downside Risk Reduction 
with Precious Metals. Int. Rev. Financ. Anal. 49, 48-58.

Broock, W.A., Scheinkman, J.A., Dechert, W.D., LeBaron, B., 1996. A test for independence based on the correlation dimension. Econom. Rev. 15, 197-235.

Ciner, C., 2001. On the long run relationship between gold and silver prices A note. Glob. Financ. J. 12, 299-303.

Cochran, S.J., Mansur, I., Odusami, B., 2012. Volatility persistence in metal returns: A FIGARCH approach. J. Econ. Bus. 64, 287-305.

Demiralay, S., Ulusoy, V., 2014. Non-linear volatility dynamics and risk management of precious metals. North Am. J. Econ. Financ. 30, 183-202.

Hammoudeh, S., Malik, F., McAleer, M., 2011. Risk management of precious metals. Q. Rev. Econ. Financ. 51, 435-441.

Hammoudeh, S., Santos, P.A., Al-Hassan, A., 2013. Downside risk management and VaR-based optimal portfolios for precious metals, oil and stocks. North Am. J. Econ. Financ. 25, 318-334.

Hammoudeh, S., Yuan, Y., 2008. Metal volatility in presence of oil and interest rate shocks. Energy Econ. 30, 606-620.

Jain, A., Biswal, P.C., 2016. Dynamic linkages among oil price, gold price, exchange rate, and stock market in India. Resour. Policy 49, 179-185. doi:10.1016/j.resourpol.2016.06.001

Jeong, K., Härdle, W.K., Song, S., 2012. A consistent nonparametric test for causality in quantile. Econom. Theory 28, 861-887.

Kang, S.H., McIver, R., Yoon, S.-M., 2016. Dynamic spillover effects among crude oil, precious metal, and agricultural commodity futures markets. Energy Econ.

Lucey, B.M., Li, S., 2015. What precious metals act as safe havens, and when? Some US evidence. Appl. Econ. Lett. 22, 35-45.

Lucey, B.M., Tully, E., 2006. The evolving relationship between gold and silver 19782002: evidence from a dynamic cointegration analysis: a note. Appl. Financ. Econ. Lett. 2, 47-53.

McCown, J.R., Shaw, R., 2016. Investment potential and risk hedging characteristics of platinum group metals. Q. Rev. Econ. Financ.

Ming, L., Yang, S., Cheng, C., 2016. The double nature of the price of gold-A quantitative analysis based on Ensemble Empirical Mode Decomposition. Resour. Policy 47, 125-131.

Morales, L., Andreosso-O'Callaghan, B., 2011. Comparative analysis on the effects of the Asian and global financial crises on precious metal markets. Res. Int. Bus. Financ. 25, 203-227.

Nishiyama, Y., Hitomi, K., Kawasaki, Y., Jeong, K., 2011. A consistent nonparametric test for nonlinear causality - Specification in time series regression. J. Econom. 165, $112-127$.

Pierdzioch, C., Risse, M., Rohloff, S., 2016. Are precious metals a hedge against exchange-rate movements? An empirical exploration using bayesian additive regression trees. North Am. J. Econ. Financ. 38, 27-38. doi:10.1016/j.najef.2016.06.002

Reboredo, J.C., 2013a. Is gold a safe haven or a hedge for the US dollar? Implications for risk management. J. Bank. Financ. 37, 2665-2676.

Reboredo, J.C., 2013b. Is gold a hedge or safe haven against oil price movements? 
Resour. Policy 38, 130-137.

Sari, R., Hammoudeh, S., Soytas, U., 2010. Dynamics of oil price, precious metal prices, and exchange rate. Energy Econ. 32, 351-362.

Sensoy, A., 2013. Dynamic relationship between precious metals. Resour. Policy 38, 504-511.

Tsay, R.S., 1986. Nonlinearity tests for time series. Biometrika 461-466.

Vivian, A., Wohar, M.E., 2012. Commodity volatility breaks. J. Int. Financ. Mark. Institutions Money 22, 395-422.

Wang, Y.S., Chueh, Y.L., 2013. Dynamic transmission effects between the interest rate, the US dollar, and gold and crude oil prices. Econ. Model. 30, 792-798.

Zhang, Z., Zhang, H.-K., 2016. The dynamics of precious metal markets VaR: A GARCHEVT approach. J. Commod. Mark. 4, 14-27. 


\section{Appendix}

This section presents the estimation strategy of Granger-causality in vector-autoregressive (VAR) framework. VAR estimation framework for two stationary time series say $\mathrm{X}$ and $\mathrm{Y}$ may be written as:

$$
\begin{aligned}
& \Delta \mathrm{X}_{t}=\alpha_{x}+\sum_{i=1}^{k} \beta_{x, i} \Delta \mathrm{X}_{t-i}+\sum_{i=1}^{k} \gamma_{x, i} \Delta \mathrm{Y}_{t-i}+\varepsilon_{x, t} \ldots \ldots . .(1) \\
& \Delta \mathrm{Y}_{t}=\alpha_{y}+\sum_{i=1}^{k} \beta_{y, i} \Delta \mathrm{Y}_{t-i}+\sum_{i=1}^{k} \gamma_{y, i} \Delta \mathrm{X}_{t-i}+\varepsilon_{y, t} \ldots \ldots . .(2)
\end{aligned}
$$

The null hypothesis $\left(\mathrm{H}_{0}\right)$ for the equations (1) is $H_{0}: \sum_{i}^{k} \gamma_{x, i}=0$ suggesting that the lagged terms of $\Delta \mathrm{Y}$ do not belong to the regression i.e., it do not Granger cause $\Delta \mathrm{X}$. Conversely, the null hypothesis $\left(\mathrm{H}_{0}\right)$ for the equations (2) is $H_{0}: \sum_{i}^{k} \gamma_{y, i}=0$, suggesting that the lagged terms of $\Delta \mathrm{X}$ do not belong to regression i.e., it do not Granger cause $\Delta \mathrm{Y}$. The joint test of these null hypotheses has been tested through Wald Chi-square $\left(\chi^{2}\right)$ test. This Wald Chisquare $\left(\chi^{2}\right)$ test gives us an indication of the 'short-term' causal effects or strict exogenity of the variables. If the coefficients of $\gamma_{x, i}$ are statistically significant, but $\gamma_{y, i}$ are not statistically significant, then $\mathrm{X}$ is said to have been caused by $\mathrm{Y}$ (unidirectional). The reverse causality holds if coefficients of $\gamma_{y, i}$ are statistically significant while $\gamma_{x, i}$ are not. But if both $\gamma_{y, i}$ and $\gamma_{x, i}$ are statistically significant, then causality runs both ways (bidirectional). Independence is identified when the $\gamma_{x, i}$ and $\gamma_{y, i}$ coefficients are not statistically significant in both the regressions. Further, non-significance of any of the 'differenced' variables which reflects only the short-term relationship, does not involve a 
violation of theory because, the theory typically has nothing to say about short-term relationships. 